\title{
Government Expenditure Ceiling and Public Debt Dynamics in a Demand-led Macromodel
}

RAFAEl SAUlo Marques Ribeiro

GILBERTO TADEU LIMA 


\title{
DEPARTMENT OF ECONOMICS, FEA-USP \\ WORKING PAPER № 2017-35
}

\section{Government Expenditure Ceiling and Public Debt Dynamics in a Demand- led Macromodel}

\author{
Rafael Saulo Marques Ribeiro (smribeiro@gmail.com) \\ Gilberto Tadeu Lima (giltadeu@usp.br)
}

\begin{abstract}
:
This article explores some aspects of the debate about the efficacy of a fiscal rule that sets a government expenditure ceiling for the stabilisation of the public debt-to-output ratio. We develop a demand-led macromodel that assumes a closed economy operating with excess capacity and show that a fiscal rule that sets a limit for government spending, excluding the payment of interests, may not ensure a non-explosive trajectory of the public debt-to-output ratio. Our model allows us to map out different outcomes in terms of the stabilisation of the public debt stemming from the process of fiscal consolidation and conclude that the commitment of the fiscal authority to comply with the ceiling by cutting government spending is less likely to stabilise the public debt-to-output ratio in economies enduring excessively high interest rates accompanied by more regressive taxation systems. Our model also suggests that a more progressive tax structure may increase the likelihood of public debt stabilisation in the long run.
\end{abstract}

Keywords: Fiscal policy; government expenditure ceiling; growth; public debt stability; income distribution.

JEL Codes: E62; 040; C01; C02. 


\title{
Government expenditure ceiling and public debt dynamics in a demand-led macromodel
}

\author{
Rafael S.M. Ribeiro \\ Faculty of Economics, Federal University of Minas Gerais, Brazil \\ Gilberto Tadeu Lima \\ Department of Economics, University of São Paulo, Brazil
}

\begin{abstract}
This article explores some aspects of the debate about the efficacy of a fiscal rule that sets a government expenditure ceiling for the stabilisation of the public debt-to-output ratio. We develop a demand-led macromodel that assumes a closed economy operating with excess capacity and show that a fiscal rule that sets a limit for government spending, excluding the payment of interests, may not ensure a non-explosive trajectory of the public debt-to-output ratio. Our model allows us to map out different outcomes in terms of the stabilisation of the public debt stemming from the process of fiscal consolidation and conclude that the commitment of the fiscal authority to comply with the ceiling by cutting government spending is less likely to stabilise the public debt-to-output ratio in economies enduring excessively high interest rates accompanied by more regressive taxation systems. Our model also suggests that a more progressive tax structure may increase the likelihood of public debt stabilisation in the long run.
\end{abstract}

Keywords: Fiscal policy, expenditure ceiling, growth, public debt stability, income distribution.

JEL: E62, O40, C01, C02.

The authors gratefully acknowledge useful comments and suggestions from Adriano dos Reis Oliveira, Clara Brenck, Eduardo Rawet, Fernando Rugitsky and Laura Carvalho on an earlier version of this paper. The first author is thankful to the São Paulo Research Foundation (FAPESP) for the grant 2016/20245-6. The usual disclaimer applies. 


\section{Introduction}

In the aftermath of the 2008 financial collapse in the U.S. followed by the Eurozone crisis, some of the world's major economies have entered a vicious cycle of slow growth, declining tax revenues and rising public debt. In this context, discussions on fiscal adjustment have gained importance in the debate amongst scholars from different academic circles and policymakers across the globe.

One way to operationalise the fiscal tightening process is through the implementation of fiscal policy rules, defined as the imposition of restrictions on fiscal parameters. The supporters of this view claim that in the absence of a sound fiscal policy rule, some factors such as uncertainties associated with the macroeconomic scenario, structural imbalances and the aging of the population can prevent the economies from growing at their full potential (Kopits and Symansky, 1998). Ljungman (2008, p. 3) states that 'fiscal rules can foster fiscal discipline by simplifying decision making, promoting an interest in sustainability issues, and reducing the scope for time-inconsistent decisions'. A large number of fiscal rules can be adopted so that the type of rule to be implemented, as well as its potential effectiveness, is intrinsically related to the political-institutional arrangement and the idiosyncratic structural condition of a particular country.

The conventional view on public debt and fiscal policy, by and large, assumes that the economies tend to operate at full employment and so fiscal expansion is likely to conduct to higher inflation. In this framework, spending cuts eventually result in lower inflation and declining public debt as a proportion of output. However, given that market economies tend to operate with either desired (in order to accommodate unexpected demand shocks) or undesired (due to insufficient demand) excess capacity, an expansionary fiscal policy may have a significant impact on the level of activity without necessarily producing unwanted inflationary effects. Further, the dynamics of the public debt-to-output ratio following spending cuts becomes much more ambiguous once the effects of public expenditure on the

level of economic activity are taken into account. Having said that, this paper contributes to the related literature by advancing a neo-Kaleckian framework that assumes an inflationfree, closed economy operating with excess capacity in order to assess some aspects of the debate about the efficacy of expenditure ceilings in promoting public debt stability. Unlike the conventional view on public debt, the post-Keynesian growth literature have 
extensively discussed the importance of a more active fiscal policy on issues such as the stabilisation of economic cycles, income distribution, and the sustainability of public debt (see e.g. Arestis and Sawyer, 2003; Hein, 2016; Palley, 2013; Ros, 1994; Setterfield, 2007; Skott, 2016; Tcherneva, 2012; You and Dutt, 1996). However, this literature has neglected the possible effects on the trajectory of public debt and the level of economic activity caused by the adoption of a government expenditure ceiling. This paper shows how a fiscal rule that merely sets a limit for public spending, excluding interest payments, may not be enough to ensure a non-explosive trajectory of the public debt to output ratio. We demonstrate that the adoption of a government expenditure ceiling is less likely to stabilise the public debt in more unequal countries with more regressive tax systems and high interest rates compared to countries with a more even income distribution, more progressive tax systems and low interest rates. However, in countries enduring excessively high levels of interest rates, our model shows that there may not exist a level of government spending as a proportion of output within the economically relevant domain that ensures the stabilisation of the public debt-to-output ratio and so the implementation of a government expenditure ceiling becomes completely ineffective.

The remainder of this paper consists of section 2 wherein we briefly discuss some aspects involving the implementation of a government expenditure ceiling and provide some preliminary, motivating empirical evidence. Section 3 presents the structure of the model in the short run. Section 4 advances the theoretical framework describing the public debt dynamics in the long run and discusses its stability properties as well as some policy implications. Lastly, we conclude.

\section{Government expenditure rules: a brief discussion}

\subsection{Government expenditure rules and its features}

This paper focuses the analysis on the adoption of a government expenditure ceiling, which is understood as the commitment made by the government not to exceed a given maximum level of expenditure previously announced. This leads us to the following questions: Why to choose a government expenditure ceiling instead of another fiscal policy rule? Ayuso-iCasals (2012) lists the comparative advantages of expenditure rules over alternative fiscal rules. The author argues that the imposition of budget balance rules may be undesirable, as 
it is likely to lead governments to adopt pro-cyclical measures and so increase the tax burden at times of low activity levels. Alternatively, cyclically adjusted budget balance rules may be more effective in ensuring fiscal discipline over time by taking into account fluctuations in the economic activity. However, one of the weaknesses of these rules is related to the uncertainties associated with the measurement of the cycle, which creates difficulties to the effective conduct of fiscal policy. The author also points out that the potential shortcomings of budget balance rules regarding its pro-cyclical features also apply to debt rules and revenue rules, since raising taxes during crisis is not usually recommended as such a measure could further reduce aggregate demand and aggravate the ongoing recession. Certainly a multi-annual deficit or revenue rule may mitigate the pro-cyclical bias. However, the problems associated with the assessment of the cycle may still emerge. The author, then, argues that such limitations of budget balanced rules, debt rules and revenue rules can be used to justify the implementation of expenditure rules. By imposing fiscal policy rules exclusively over the part of the budget that the government controls, the uncertainty regarding the attainment of the fiscal target is reduced and the goals of stability and predictability of the long-run public debt trajectory and the economic fluctuations are more easily achieved. Additionally, expenditure ceilings can be more clearly established, simpler to monitor and more transparent in terms of accountability and enforcement than other types of rules.

Another important aspect of this discussion is the coverage of government spending. On the one hand, fiscal discipline requires all public expenditures to be subject to the ceiling. However, Ljungman (2008) states that other objectives, such as macroeconomic stability, may justify excluding from the ceiling some components of the government spending. In the short term, a large part of entitlements, such as health care and social security benefits, is fixed. Nevertheless, it is considered that through changes in legislation and negotiations in the congress, in the medium term these social benefits can also be included under the ceiling. Thus, it is up to the policy maker to decide which items that constitute government spending may fall outside the constraints imposed by the expenditure ceiling. The main candidates are interest payments on treasury bonds and cyclically-sensitive public spending items. 
In fact, interest payments are usually excluded from the expenditure ceiling. There are some arguments to justify this measure. Short-term interest rate fluctuations may affect the structure of the government debt. If these interest payments were included under the ceiling, an increase in the interest rate could force the government to reduce spending in other areas. Similarly, a reduction in interest would enlarge the fiscal space for the government to expand its spending in other key areas. Therefore, it is argued that shortterm interest rate fluctuations tend to cancel out over time, which makes it difficult to justify the inclusion of debt service under the ceiling with the aim of maintaining the sustainability of the long-run public debt. A stronger argument against the inclusion of interest payments under the ceiling is related to the fact that such a measure could create incentives for the government to sell public assets in order to reduce the stock of public debt.

There is also a debate about whether or not to include spending restrictions on items that are sensitive to the business cycle, such as unemployment insurance and corporate subsidy programs with the aim of reheating the labour market. The possibility of smoothing economic fluctuations through fiscal corrective measures depends heavily on the comprehensiveness of the ceiling ${ }^{1}$. However, despite the debate about the effectiveness of countercyclical measures in the literature, there seems to be some consensus in favor of allowing automatic stabilisers to operate freely (Perroti, 2005). As aforementioned, it is expected that in times of decline in the level of economic activity, spending will expand due to the increase in the granting of benefits such as unemployment insurance and subsidies for companies, thus helping to recover the GDP growth trajectory.

Notably, there is a large consensus amongst a number of scholars and policymakers that setting a government expenditure ceiling associated with greater government commitment to comply with the fiscal rule seems to be the best way to ensure long-run public debt sustainability and growth. Nevertheless, the presumed efficacy of such a policy recommendation is heavily based on empirical evidence and case studies conducted exclusively for OECD and EU countries (Alesina and Bayoumi, 1996; Badinger, 2009; Debrun et al, 2008; Hallerberg et al, 2007; von Hagen, 1991; von Hagen and Wolff, 2006).

\footnotetext{
${ }^{1}$ Case studies are not able to show the effectiveness of including or excluding such expenditures under the ceiling limits. In countries like the Netherlands and Sweden these expenses are included in the ceiling. In the case of Finland, most of the cycle-sensitive expenditure is outside the ceiling (Ljungman, 2008).
} 
And yet, in the case of developing countries and emerging markets enduring relatively high levels of interest rates, the theoretical justification for the simple adoption of a ceiling on public expenditure may seem like a patch of new clothes on an old garment, since this type of rule may even increase the instability of the long-run public debt by diminishing the effects of automatic fiscal stabilisers designed to mitigate economics fluctuations. The use of active fiscal policy as an instrument of economic stabilisation may be especially needed in times of poor economic performance accompanied by soaring risk premium and increased interest payments and so the adoption of a ceiling may unnecessarily prolong economic downturns and economic crises.

\subsection{An empirical assessment using quantile regressions}

Now we conduct a motivating, preliminary empirical exercise in order to merely illustrate the relationship between the adoption of a government expenditure ceiling and the dynamics of the public debt as a proportion of output across groups of countries at different stages of economic development.

The sample consists of 29 developed and 17 developing countries ${ }^{2}$ and covers the period 1985-2015 (see the list of countries in the Appendix 1). The dependent variable in the model is the variation of the public debt (\%GDP) and the independent variables are the lagged variation of the public debt (\%GDP), general government net lending (\%GDP), GDP growth rate and a dummy accounting for the implementation of government expenditure rules (see the descriptions of the variables in the Appendix 2).

In this empirical model we will use quantile regression with panel data to estimate the parameters of interest. In their seminal work, Koenker and Bassett (1978) develop a methodology that allows us to estimate the relationship between a vector of regressors and different percentiles of the response variable. In the standard conditional mean analysis, the minimisation of the sum of squares of residuals ensures that the same number of observations above and below the median is obtained. Quantile regression, on the other hand, allows us to map out the partial effect of a specific regressor on any point of the conditional distribution of the dependent variable. For instance, quantile regression permits to describe how regressor variables affect, not only the median, but also all the $\tau$ th quantile

\footnotetext{
${ }^{2}$ We divide the countries in advanced and emerging markets according to the IMF's WEO Database classification.
} 
of the regressand. Moreover, this methodology is robust to asymmetric conditional distributions.

The first step is to determine the order of integration of each variable. Then, we conduct panel unit root tests for all the variables of the model (see the results in Appendix 3) and conclude that the baseline equation to be tested is the following:

$$
\Delta D e b t_{i, t}=\beta_{0}(\tau)+\beta_{1}(\tau) \Delta D e b t_{i, t-1}+\beta_{2}(\tau) E R_{i, t}+\beta_{3}(\tau) G G N L_{i, t}+\beta_{4}(\tau) \text { Growth }_{i, t}
$$

where $\tau \in(0,1)$; the subscripts $i$ and $t$ account for country and time-period, respectively; Debt denotes the public debt-GDP ratio; $E R$ is the expenditure rule dummy which is equal to one during the period $t$ when country $i$ adopts the rule and zero otherwise; GGNL stands for general government net lending as a proportion of GDP; and Growth is GDP growth rate.

Given the panel data structure of our sample, we will estimate the quantile regression on stacked data without allowing the autoregressive term to cut across cross-sections. It is worth saying that it is out of the scope of this work to treat unobserved effects and endogeneity problems ${ }^{3}$. Thus, we are simply testing if the adoption of expenditure rules may be associated with the stabilisation of the public debt-GDP ratio. Additionally, we want to provide an answer to the following question: Do expenditure rules affect differently small and large variations of the public debt-GDP ratio? In other words, we seek to assess if countries exhibiting an explosive public debt trajectory can be better off by adopting a government expenditure rule. Since variations in the lower (higher) quantiles are considered small (large), the quantile regression approach permits the description of the effectiveness of expenditure rules for different degrees of variation of the public debt-GDP ratio.

So let us examine both figures below:

\section{[FIGURE 1 ABOUT HERE]}

\footnotetext{
${ }^{3}$ In order to correctly estimate the baseline equation above one needs to take into account the existence of unobserved time- and country-specific effects. Normally, this problem can be solved by allowing into the model period- and country-specific dummy variables. Moreover, simultaneity or reverse causality must be properly controlled for, since the explanatory variables tend to be endogenous to the public debt dynamic.
} 
[FIGURE 2 ABOUT HERE]

Let us analyse first the variable 'Expenditure Rule' in the upper-left quadrant of Figures 1 and 2. Its impact on variations of public debt-GDP ratio is negative and statistically significant between the 20th and the 80th quantiles ${ }^{4}$, thus implying that, in advanced countries, periods in which public spending rules are being adopted are linked to a decrease in the public debt-GDP ratio (the quantile curve is below the zero line for all the percentiles). Moreover, note that the implementation of expenditure rules seems to be more effective in advanced countries exhibiting larger variations of public debt-GDP ratio, which means that these rules are indeed associated with public debt reductions in these countries. Meanwhile, Figure 2 shows that the adoption of government spending rules in developing countries may affect adversely the public debt-GDP trajectory. In these economies, the impact of the implementation of expenditure rules on the annual variation of the public debt-GDP ratio is positive and non-significant for all the percentiles of the conditional distribution (the quantile curve is now above the zero line for all the percentiles). Lastly, it is worth mentioning that all the other variables exhibit their expected signs in both groups of countries. That is, the lagged variation of public debt-GDP ratio affects positively the current variation of the public debt-GDP, while both government net lending and GDP growth reduce the public debt variation across most of the quantiles of the conditional distribution.

Although preliminary, our estimates suggest that, in spite of the variety of institutional forms of expenditure rules considered in the sample, by and large, setting limitations to government spending may not be enough to reduce and/or stabilise the public debt-GDP ratio in developing economies. In the next section, we move on to the analysis of a formal model and the conditions under which the implementation of a government expenditure ceiling may or may not yield greater stability of the government debt-to-output ratio. We seek to show that some salient features commonly associated with less developed countries tend to reduce the capacity of expenditure rules to tame public debt. Lastly, it is worth mentioning that, for simplicity, in the next sections we model only one type of expenditure

\footnotetext{
${ }^{4}$ For the 30 th percentile it is significant at $10 \%$.
} 
rule as a representative case. We assume that the government sets a limit on public spending as a percentage of output.

\section{Capacity utilisation, capital accumulation and output growth in the short-run}

Suppose a closed economy with excess capacity utilisation that produces one type of good which is used for consumption and investment ${ }^{5}$. Given that the economy operates below full capacity, the rate of capacity utilisation adjusts to accommodate any excess demand or supply. Also assume that the functional distribution of income before taxation remains constant and that the price level of the economy does not change either, thus implying that the model is cast in real terms; this is a plausible assumption in an economy characterised by the existence of excess capacity, constant unit labour cost and constant mark-up factor. There are two classes in the economy, workers and capitalists. Workers earn only wages and consume all their income. Capitalists are divided into entrepreneurs and rentiers. While entrepreneurs earn profits of enterprises and save a constant fraction of their income, rentiers earn income from the stock of credit granted to the government at a given interest rate set by the central bank and also save a constant fraction of their income. Suppose as well that there is not substitutability between labour, physical capital and financial assets. Thus, the function of aggregate consumption $(C)$ as a proportion of the potential output $\left(Y_{p}\right)$ is given by:

$$
c v=\frac{C}{K} \frac{K}{Y_{p}}=\left(1-\tau_{w}\right) \sigma u v+(1-s)\left(1-\tau_{c}\right)[(1-\sigma)+r \lambda] u v
$$

where $c=C / K$ is the ratio of aggregate consumption to the stock of capital $(K), v=$ $K / Y_{p}, \tau_{w}$ and $\tau_{c}$ are the tax rates on labour and capital income, $\sigma$ is the wage share of income, $u$ is equal to the ratio of output $(Y)$ to the stock of capital, $s$ is the marginal propensity to save of capitalists, $r$ is the real interest rate (since prices are constant in the model, nominal interest rate equals real interest rate), $\lambda=B / Y$ is the ratio of the stock of public debt $(B)$ to output. To save notation, it is assumed henceforth that the ratio of the capital stock to the potential output equals unity $(v=1)$ and so $u$ denotes the capacity utilisation.

\footnotetext{
${ }^{5}$ This model is close in spirit to Dutt (1984) and You and Dutt (1996).
} 
Assuming a simplified investment function where capital accumulation plans are positively related to the current rate of net profits of firms, which is taken as a proxy for the expected profits (Kalecki, 1971; Robinson, 1956, 1962), we have:

$$
i=\frac{I}{K}=\alpha_{0}+\alpha_{1}\left(1-\tau_{c}\right)(1-\sigma) u
$$

where $i=I / K$ is the total investment $(I)$ as a proportion of the capital stock, and $\alpha_{0}, \alpha_{1}>$ 0 are parameters. Our model assumes no depreciation of physical capital, for simplicity.

Finally, we assume that government expenditure $(G)$, including the consumption of goods and services, are given as a fixed proportion of capital stock:

$$
g=\frac{G}{K}=\left(z_{\gamma}+\gamma_{T}\right) u
$$

where $\gamma=G / Y, \gamma_{T}$ is the government-stipulated expenditure ceiling as a proportion of output, and $z_{\gamma} \equiv \gamma-\gamma_{T}$ is the expenditure gap. Note that for any positive (negative) value of the expenditure gap $z_{\gamma}$ the government is spending above (below) the ceiling. Since this study aims to analyse the consequences of fiscal tightening, the initial condition of the model assumes that $z_{\gamma}>0$.

Since income in a demand-led closed economy is determined by the sum of consumption, investment, and government spending, we have:

$$
u=c+i+g
$$

Assuming that $\tau_{w}, \sigma, r, s, \lambda, z_{\gamma}$ and $\gamma_{T}$ remain constant in the short run, by substituting from (1) - (3) into (4), and then solving for $u$, we obtain:

$$
u^{*}=\frac{\alpha_{0}}{\mu-z_{\gamma}-\gamma_{T}}
$$

where $\mu=1-\left(1-\tau_{w}\right) \sigma-(1-s)\left(1-\tau_{c}\right)[(1-\sigma)+r \lambda]-\alpha_{1}\left(1-\tau_{c}\right)(1-\sigma)$. Then $u^{*}$ is the degree of capital capacity utilisation that balances the goods market in the short run. The stability condition of the goods market equilibrium in (5) is $\mu-z_{\gamma}-\gamma_{T}>0$, which is equivalent to, all else constant, the sum of demand leakages being more responsive 
to changes in capital capacity utilisation than the sum of demand injections. Note that the wage share is directly related to the equilibrium capacity utilisation $u^{*}$. Conversely, given a sufficiently low value of $\alpha_{1}$, a tax system that disproportionally burdens the lower class $\left(\Delta \tau_{w}>0\right.$ accompanied by $\left.\Delta \tau_{c}<0\right)$ impacts negatively on aggregate demand. Lastly, an expansionary fiscal policy, or a raise in $z_{\gamma}$, subject to the constraint given by $\mu-z_{\gamma}-\gamma_{T}>$ 0 , spurs aggregate demand.

Substituting (5) into (2), we obtain:

$$
i=\alpha_{0}+\alpha_{1} \frac{\alpha_{0} s\left(1-\tau_{c}\right)(1-\sigma)}{\mu-z_{\gamma}-\gamma_{T}}
$$

Equation (6) represents the equilibrium accumulation rate in the short run.

Lastly, we obtain the output growth rate in the short-run equilibrium. Considering that the capital capacity utilisation is constant, in equilibrium we have $\dot{Y} / Y=\dot{Y}_{p} / Y_{p}=I / K$. This gives:

$$
y=\frac{\dot{Y}_{p}}{I} i v
$$

where $y=\dot{Y} / Y$. If $v=1$, then $\dot{Y}_{p} / I=1$ as well. Equation (7), then, becomes:

$$
y=i
$$

That is, the output growth rate equals the rate of capital accumulation.

Next we develop the formal framework describing the public debt dynamics and discuss to which extent a government expenditure ceiling can contribute to the stabilisation of the public debt ratio over time.

\section{The public debt and the government spending: the long-run dynamics}

\subsection{The stability analysis}

As discussed in the introduction, setting a ceiling for government spending, not including interest payments, has been one of the main economic policy recommendations aimed at stabilising the business cycles and the trajectory of public debt over time. The aim of this 
section is to compare the stability conditions of the public debt dynamics before and after the implementation of a government expenditure ceiling. At this point, it is worth asking the following questions: Why, in a closed economy framework, should a sovereign government that issues treasury bonds in national currency care about the public debt trajectory? A quick answer to this question is that after a certain threshold the supply of bonds may exceed the demand of the public for bonds, thus forcing the government to finance new debt with seignorage. Then, one may continue to ask: Why, in an economy with excess capacity, cannot the government monetise the public debt with domestic currency until it attains full employment with stable inflation? As a possible rejoinder, we can argue that the government does not have unlimited capacity to force the public to always accept additional money. This stems, for instance, from the idea that the acceptability of money is a social convention. Dequech $(2013$, p. 268) states that "if people do not believe that the state will be able to enforce tax liabilities, they will stop accepting that which the state establishes as the means of payments of taxes". In moments of economic crises and soaring indebtedness, governments tend to lose legitimacy, thus reducing their capacity to impose taxes. In this scenario, the public may refuse to accept the current money and start using alternative means of payment to conduct domestic transactions (Wray, 1998). Notably, the limitations to the issuance of fiat money may be even more stringent in developing countries with weaker currencies in the international monetary system. Therefore, even sovereign states that issue public bonds in their own currencies should pay attention to their level of indebtedness.

That said, let us continue with the formal model. In the long-run dynamics the short-run equilibrium values of the variables are consistently attained so that in the long run the economic dynamics can be analysed through the behaviour of two short-run state variables, namely, the expenditure gap and the public debt-output ratio. For simplicity, assume that the high-powered money remains constant and so the overall government spending is financed through the issuing of public debt, as follows:

$$
\dot{B}=(G-T)+r B
$$

where $T$ accounts for the total tax revenue.

By definition, taxes as a proportion of output are given by: 


$$
\begin{gathered}
\frac{T}{K}=\rho u=\tau_{w} \sigma u+\tau_{c}[(1-\sigma) u+r \lambda u] \\
\rho=\tau_{w} \sigma+\tau_{c}[(1-\sigma)+r \lambda]
\end{gathered}
$$

where $\rho=T / Y$.

Given that the short-run equilibrium in the goods market is always satisfied, by substituting equations (9) and (10) into the time differential of $\lambda$, which is given by $\dot{\lambda}=\lambda(\dot{B} / B-i)$, we obtain:

$$
\dot{\lambda}=z_{\gamma}+\gamma_{T}-\tau+\left[\left(1-\tau_{c}\right) r-\alpha_{0}-\alpha_{1} \frac{\alpha_{0} s\left(1-\tau_{c}\right)(1-\sigma)}{\mu-z_{\gamma}-\gamma_{T}}\right] \lambda
$$

where $\tau=\tau_{w} \sigma+\tau_{c}(1-\sigma)$ denotes the tax on labour income and physical capital income. Note that the total tax revenue as a proportion of output also includes the tax on financial income, that is $\rho=\tau+\tau_{c} r \lambda$.

The next step is to define the dynamical equation of government spending constrained by a government expenditure ceiling. This equation of motion can be defined as follows:

$$
\dot{z}_{\gamma}=-\theta\left(z_{\gamma}-z_{\gamma}^{e}\right)
$$

where $z_{\gamma}^{e} \geq 0$ is the expenditure gap desired by the fiscal authority, and $\theta$ is a parameters that accounts for the speed of spending cuts. Equation (12) states that when current expenditure gap as a proportion of output $z_{\gamma}$ is above the desired expenditure gap $z_{\gamma}^{e}$, public spending should be reduced until it converges towards the desired expenditure gap. On the other hand assume that it is irrational from the policymaker standpoint to maintain the current level of public expenditure systematically below the ceiling; this is a plausible assumption, as the maintenance of the current government spending below the ceiling over a prolonged period of time may underheat the labour market and engender social pressures for corrective fiscal policy measures. Note that, if the government is fully and credibly committed not to consistently spend beyond the ceiling, than $\gamma=\gamma_{T}$ and hence $z_{\gamma}^{e}=0{ }^{6}$. However, as a more general case, assume that initially we have $z_{\gamma}^{e}>0$.

\footnotetext{
${ }^{6}$ It is out of the scope of this paper to address the social costs stemming from the impossibility of meeting the ceiling. For a discussion on how the imposition of fiscal rules may encourage policymakers to engage in
} 
Now assume that the risk and liquidity premia set by the rentiers is positively related to the public debt-output ratio, as follows:

$$
r=\eta_{0}+\eta_{1} \lambda
$$

where $\eta_{0}$ and $\eta_{1}$ are parameters. From rentiers' standpoint, the higher the public debt as a proportion of output, the higher the default risk, and hence the higher the risk and liquidity premia lenders will require in order to keep financing new government spending. However, one should expect that sufficiently low levels of indebtedness variations in the public debtoutput ratio will not affect interest rates as the risk of default may be negligible. In the same manner, for an excessively high level of public debt-output ratio rentiers will not be willing to grant more credit to the government and so supply of credit is drastically interrupted as lenders consider that the government will fail to fulfill its obligation. Thus, it is assumed that interest rates only respond to variations in the public debt-output ratio within the domain $\lambda_{\min }<\lambda<\lambda_{\max }$, where $\lambda_{\min }$ and $\lambda_{\max }$ are, respectively, the maximum and minimum values of $\lambda$, which are exogenously given. Therefore, in order to simplify the analysis, suppose that the level of public debt-output ratio in the model falls within the domain given by $\lambda_{\min }<\lambda<\lambda_{\max }$.

The equilibrium level of public debt that satisfies the condition $\dot{\lambda}=\dot{z}_{\gamma}=0$ in the long run is a forth degree equation and so it may have up to four real roots within the economically relevant domain $\lambda_{\min }<\lambda<\lambda_{\max }$. For simplicity, assume that the system $\dot{\lambda}=\dot{z}_{\gamma}=0$ has only one solution within this domain, which is $\left(z_{\gamma}^{e} \geq 0, \lambda^{e}>0\right)$.

Equations (11) and (12) form a two-dimensional dynamical system. The Jacobian matrix evaluated at the equilibrium solution $\left(z_{\gamma}^{e}, \lambda^{e}\right)$ is constituted by the following elements:

$$
\begin{aligned}
& J_{11}=\frac{\partial \dot{\lambda}}{\partial \lambda}=\left(1-\tau_{c}\right)\left(\eta_{0}+2 \eta_{1} \lambda\right)-\alpha_{0}-\alpha_{1} \alpha_{0} s\left(1-\tau_{c}\right)(1-\sigma)\left[\frac{\mu-z_{\gamma}^{e}-\gamma_{T}-\lambda^{e} \mu_{\lambda}}{\left(\mu-z_{\gamma}^{e}-\gamma_{T}\right)^{2}}\right] \\
& J_{12}=\frac{\partial \dot{\lambda}}{\partial z_{\gamma}}=1-\frac{\alpha_{1} \alpha_{0} \lambda^{e}}{\left(\mu-z_{\gamma}^{e}-\gamma_{T}\right)^{2}}
\end{aligned}
$$

'creative accounting' practices, thus reducing the transparency in the government budget, see Milesi-Ferreti (2003). 


$$
\begin{aligned}
& J_{21}=\frac{\partial \dot{z}_{\gamma}}{\partial \lambda}=0 \\
& J_{22}=\frac{\partial \dot{z}_{\gamma}}{\partial z_{\gamma}}=-\theta
\end{aligned}
$$

where $\mu_{\lambda}=-(1-s)\left(1-\tau_{c}\right)\left(\eta_{0}+2 \eta_{1} \lambda\right)<0$.

Note that $J_{11}$ and $J_{12}$ are ambiguously signed. The stability condition of the system requires a negative trace and a positive determinant of the Jacobian matrix evaluated at the equilibrium solution. Since $J_{22}$ is invariably negative and $J_{21}$ is equal to zero, the stability of the system depends exclusively on the sign of $J_{11}$. That is, if $J_{11}<0$, then $\operatorname{Tr}(J)=J_{11}+$ $J_{22}<0$ and $\operatorname{Det}(J)=J_{11} J_{22}-(0) J_{21}>0$, thus implying that the system is stable; on the other hand, if $J_{11}>0$, then $\operatorname{Tr}(J)=J_{11}+J_{22} \gtrless 0$ and $\operatorname{Det}(J)=J_{11} J_{22}-(0) J_{21}<0$, thereby resulting in a saddle-point equilibrium solution.

Figures 3 and 4 below illustrate both the unstable and the stable equilibria solution of the linearised dynamical system in the long run, respectively:

\section{[FIGURE 3 ABOUT HERE]}

\section{[FIGURE 4 ABOUT HERE]}

Given the importance of the sign of $J_{11}$ for the stability of the public debt in the long run, we raise the following question: Does the implementation of a ceiling change the stability condition of the public debt-output trajectory? In terms of the model, we want to compare two different scenarios: (i) The stability condition of the public debt trajectory before the fiscal adjustment when $z_{\gamma}^{e}=z_{\gamma 0}>0$; (ii) The stability condition of the economy after the fiscal adjustment when $z_{\gamma}^{e}=0$. In (i) it is assumed that the government keeps constant the level of current government spending over time. In (ii) we have the case in which the fiscal authority makes a binding commitment with the fiscal rule and so effectively cuts public spending in order to meet the ceiling.

In order to address this question, consider $J_{11}=0$ and rearrange the terms, as follows:

$$
\frac{\psi b^{2}-\alpha_{1} \alpha_{0} s\left(1-\tau_{c}\right)(1-\sigma) b+\alpha_{1} \alpha_{0} s\left(1-\tau_{c}\right)(1-\sigma) \lambda^{e} \mu_{\lambda}}{b^{2}}=0
$$


where $\psi=\left(1-\tau_{c}\right)\left(\eta_{0}+2 \eta_{1} \lambda\right)-\alpha_{0} \gtrless 0$ and $b=\mu-z_{\gamma}^{e}-\gamma_{T}>0$. Therefore, the stability condition of the dynamical system is $\psi b^{2}-\alpha_{1} \alpha_{0} b+\alpha_{1} \alpha_{0} \lambda^{e 0} \mu_{\lambda}<0$. The real roots of the quadratic equation in (14) are given by:

$$
\begin{aligned}
& b_{1}=\frac{\alpha_{1} \alpha_{0} s\left(1-\tau_{c}\right)(1-\sigma)-\sqrt{\Delta}}{2 \psi} \\
& b_{2}=\frac{\alpha_{1} \alpha_{0} s\left(1-\tau_{c}\right)(1-\sigma)+\sqrt{\Delta}}{2 \psi}
\end{aligned}
$$

where $\Delta=\left[\alpha_{1} \alpha_{0} s\left(1-\tau_{c}\right)(1-\sigma)\right]^{2}-4 \psi \alpha_{1} \alpha_{0} s\left(1-\tau_{c}\right)(1-\sigma) \lambda^{e 0} \mu_{\lambda} \geq 0$. Since $\mu_{\lambda}<$ 0 , the term $\Delta$ cannot be less than zero. Additionally, given that $\mu_{\lambda}$ is strictly negative, we also conclude that $\alpha_{1} \alpha_{0} s\left(1-\tau_{c}\right)(1-\sigma)<\sqrt{\Delta}$. ${ }^{7}$ To save notation, let us examine exclusively the more general case in which the term $\Delta$ is strictly positive.

From equation (14), now we analyse the stability properties of two possible scenarios: A) $\psi<0$; and B) $\psi>0$. Scenario A (Scenario B) presents an economy where interest rate after taxation, $\left(1-\tau_{c}\right)\left(\eta_{0}+2 \eta_{1} \lambda\right)$, is lower (higher) than the autonomous component of the investment function, $\alpha_{0}{ }^{8}$. Since developing countries usually exhibit higher interest rates, it is plausible to state that scenario A (in which $\psi<0$ ) is more likely to illustrate a developed economy, while the scenario B (wherein $\psi>0$ ) tends to represent the case of a developing country.

\section{Scenario A - Developed economy $(\psi<0)$}

The graphical representation of the stability condition (14) is given by:

\section{[FIGURE 5 ABOUT HERE]}

From equation (14), we know that $b$ is strictly positive, $b=\mu-z_{\gamma}^{e}-\gamma_{T}>0$, in order to satisfy the stability condition in the goods market. Given that $\psi<0$ and $\alpha_{1} \alpha_{0} s(1-$ $\left.\tau_{c}\right)(1-\sigma)<\sqrt{\Delta}$, the term $b_{2}$ is strictly negative and hence falls outside the economically

7 Proof: Given that $\mu_{\lambda}<0$, we have $\sqrt{\left[\alpha_{1} \alpha_{0} s\left(1-\tau_{c}\right)(1-\sigma)\right]^{2}-4 \psi \alpha_{1} \alpha_{0} s\left(1-\tau_{c}\right)(1-\sigma) \lambda^{e 0} \mu_{\lambda}} \geq$ $\sqrt{\left[\alpha_{1} \alpha_{0} s\left(1-\tau_{c}\right)(1-\sigma)\right]^{2}}=\left[\alpha_{1} \alpha_{0} s\left(1-\tau_{c}\right)(1-\sigma)\right]$.

${ }^{8}$ Note that, by equation (13), we know that $r=\eta_{0}+\eta_{1} \lambda$, thus implying that $\psi$ can be rewritten as $\psi=$ $\left(1-\tau_{c}\right) r-\alpha_{0}$. So, if interest rate is sufficiently low (high), we have $\psi$ lesser (greater) than zero. 
relevant domain $b>0$. Therefore, let us examine the stability conditions both before and after the fiscal adjustment around $b_{1}>0$.

Assume in the first case that the expenditure gap before de fiscal adjustment $z_{\gamma B}^{*}$ yields $b_{B}^{*}>b_{1}$. Suppose also that the government is fully committed to meet the ceiling and so the expenditure gap after the adjustment is $z_{\gamma A}^{*}=0$ which gives $b_{A}^{*}>b_{B}^{*}>b_{1}$. Note in Figure 5 that the public debt-output ratio is in a stable path before and after the fiscal adjustment. In terms of the model, we have the following stability condition:

$$
\begin{gathered}
b_{B}^{*}=\mu-z_{\gamma B}^{*}-\gamma_{T}>b_{1}=\frac{\alpha_{1} \alpha_{0} s\left(1-\tau_{c}\right)(1-\sigma)-\sqrt{\Delta}}{2 \psi}>0 \\
\Downarrow \\
0=z_{\gamma A}^{*}<z_{\gamma B}^{*}<\mu-\gamma_{T}-\left(\frac{\alpha_{1} \alpha_{0} s\left(1-\tau_{c}\right)(1-\sigma)-\sqrt{\Delta}}{2 \psi}\right)<\mu-\gamma_{T}
\end{gathered}
$$

Since both $z_{\gamma B}^{*}>0$ and $z_{\gamma A}^{*}=0$ satisfy simultaneously the stability condition of the dynamical system $J_{11}<0$ and the stability condition of the goods market $b=\mu-z_{\gamma}^{e}-$ $\gamma_{T}>0$ we conclude that in this case the public debt-output ratio is stable before and after the fiscal adjustment. Figure 5.1 illustrates this dynamics.

\section{[FIGURE 5.1 ABOUT HERE]}

Assume now the case in which the expenditure gap before de fiscal adjustment $z_{\gamma B}^{* *}$ yields $b_{B}^{*}<b_{1}$. It implies that in the second case the expenditure gap before the fiscal adjustment is greater that the expenditure gap before de adjustment in the first case shown above. Again, the expenditure gap after the adjustment is $z_{\gamma A}^{*}=0$ which gives $b_{B}^{*}<b_{1}<$ $b_{A}^{*}$. We can see in Figure 5 that the public debt-output ratio starts in an unstable trajectory but the austerity measures effectively stabilise the public debt dynamics. Thus, we have the following stability condition:

$$
b_{B}^{*}=\mu-z_{\gamma B}^{*}-\gamma_{T}<b_{1}=\frac{\alpha_{1} \alpha_{0} s\left(1-\tau_{c}\right)(1-\sigma)-\sqrt{\Delta}}{2 \psi}>0
$$




$$
0=z_{\gamma A}^{*}<\mu-\gamma_{T}-\left(\frac{\alpha_{1} \alpha_{0} s\left(1-\tau_{c}\right)(1-\sigma)-\sqrt{\Delta}}{2 \psi}\right)<z_{\gamma B}^{*}<\mu-\gamma_{T}
$$

The expenditure gap before the adjustment satisfies the stability condition in the goods market $b=\mu-z_{\gamma}^{e}-\gamma_{T}>0$, but not the dynamical system stability condition given by $J_{11}<0$. However, in this case, the government may stabilise the public debt-output ratio by meeting the expenditure ceiling. Also note that if $z_{\gamma B}^{*}$ violates the goods market stability condition, then $b<0$ which is impossible in the model. See Figure 5.2 below.

\section{[FIGURE 5.2 ABOUT HERE]}

There is a third case where we have $\mu-\gamma_{T}<\left|\left(\alpha_{1} \alpha_{0} s\left(1-\tau_{c}\right)(1-\sigma)-\sqrt{\Delta}\right) / 2 \psi\right|$, which is equivalent to:

$$
\mu-\gamma_{T}-\left(\frac{\alpha_{1} \alpha_{0} s\left(1-\tau_{c}\right)(1-\sigma)-\sqrt{\Delta}}{2 \psi}\right)<0=z_{\gamma A}^{*}<z_{\gamma B}^{*}<\mu-\gamma_{T}
$$

In this case, the stability condition $J_{11}<0$ does not hold and so the public debt-output trajectory is unstable before and after the fiscal adjustment. Figure 5.3 shows this case.

\section{[FIGURE 5.3 ABOUT HERE]}

Therefore, the model allows us to map out three different cases, as shown in Table 1:

\section{[TABLE 1 ABOUT HERE]}

To sum up, in an economy where interest rates after taxation are sufficiently low, $\psi<0$, governments are more likely to stabilise the dynamics of the public debt-output ratio.

\section{Scenario B - Developing economy $(\psi>0)$}

Now, the graphical representation of the stability condition (14) is given by: 
[FIGURE 6 ABOUT HERE]

Again, from equation (14), we know that $b$ must strictly positive when the stability condition in the goods market holds. Given that $\psi>0$ and $\alpha_{1} \alpha_{0}<\sqrt{\Delta}$, the term $b_{1}<0$ does not satisfy such a condition and hence falls outside the economically relevant domain, that is $b>0$. That said, we, then, analyse the stability conditions both before and after the fiscal adjustment around $b_{2}>0$.

In the first case, the expenditure gap before de fiscal adjustment $z_{\gamma B}^{*}$ yields $b_{B}^{*}<b_{2}$. If the government effectively meets the ceiling, then the expenditure gap after the adjustment is $z_{\gamma A}^{*}=0$, which gives $b_{B}^{*}<b_{A}^{*}<b_{2}$. If we assume at first that $\mu-\gamma_{T}<\left|\left(\alpha_{1} \alpha_{0} s\left(1-\tau_{c}\right)(1-\sigma)+\sqrt{\Delta}\right) / 2 \psi\right|$, then the public debt-output ratio can be stable before and after the government carries out the austerity measures. More formally, we have the following stability condition:

$$
\begin{gathered}
b_{B}^{*}=\mu-z_{\gamma B}^{*}-\gamma_{T}<b_{2}=\frac{\alpha_{1} \alpha_{0} s\left(1-\tau_{c}\right)(1-\sigma)+\sqrt{\Delta}}{2 \psi}>0 \\
\Downarrow \\
\mu-\gamma_{T}-\left(\frac{\alpha_{1} \alpha_{0} s\left(1-\tau_{c}\right)(1-\sigma)+\sqrt{\Delta}}{2 \psi}\right)<0=z_{\gamma A}^{*}<z_{\gamma B}^{*}<\mu-\gamma_{T}
\end{gathered}
$$

Note that both $z_{\gamma B}^{*}$ and $z_{\gamma A}^{*}$ satisfy the goods market and the dynamical system stability conditions. See Figure 6.1 below for a graphical representation.

\section{[FIGURE 6.1 ABOUT HERE]}

In the second case, suppose once more that the expenditure gap before de fiscal adjustment given by $z_{\gamma B}^{*}$ yields $b_{B}^{*}<b_{2}$. However, assume now that $\mu-\gamma_{T}>$ $\left|\left(\alpha_{1} \alpha_{0} s\left(1-\tau_{c}\right)(1-\sigma)+\sqrt{\Delta}\right) / 2 \psi\right|$. It means that for $z_{\gamma A}^{*}=0$ the stability condition of the dynamical system does not hold after the fiscal adjustment. In terms of the model, we obtain the following stability condition: 


$$
\begin{gathered}
b_{B}^{*}=\mu-z_{\gamma B}^{*}-\gamma_{T}<b_{2}=\frac{\alpha_{1} \alpha_{0} s\left(1-\tau_{c}\right)(1-\sigma)+\sqrt{\Delta}}{2 \psi}>0 \\
\Downarrow \\
0=z_{\gamma A}^{*}<\mu-\gamma_{T}-\left(\frac{\alpha_{1} \alpha_{0} s\left(1-\tau_{c}\right)(1-\sigma)+\sqrt{\Delta}}{2 \psi}\right)<z_{\gamma B}^{*}<\mu-\gamma_{T}
\end{gathered}
$$

In the second case the expenditure gap before the fiscal adjustment given by $z_{\gamma B}^{*}$ satisfies the stability condition of the dynamical system represented by $J_{11}<0$. However, by meeting the expenditure ceiling, the government violates the stability properties of the system and so the commitment with the fiscal rule may set the public debt-output trajectory in an explosive path over time. Therefore, in this case, the fiscal authority is better off by not cutting public expenditure since it maintains the public debt-output ratio in a stable trajectory. The second case is shown in Figure 6.2.

\section{[FIGURE 6.2 ABOUT HERE]}

We also have the third case in which expenditure gap before de fiscal adjustment $z_{\gamma B}^{*}$ yields $b_{2}<b_{B}^{*}$. It means that in this case the expenditure gap before the fiscal adjustment is greater than the expenditure gap before de adjustment in the first two cases of scenario B. Again, since the expenditure gap after the adjustment is $z_{\gamma A}^{*}=0$, we have $b_{2}<b_{B}^{* *}<b_{A}^{* *}$. Thus, we have the following stability condition:

$$
\begin{gathered}
b_{B}^{*}=\mu-z_{\gamma B}^{*}-\gamma_{T}<b_{2}=\frac{\alpha_{1} \alpha_{0} s\left(1-\tau_{c}\right)(1-\sigma)+\sqrt{\Delta}}{2 \psi} \\
\Downarrow \\
0=z_{\gamma A}^{*}<z_{\gamma B}^{*}<\mu-\gamma_{T}-\left(\frac{\alpha_{1} \alpha_{0} s\left(1-\tau_{c}\right)(1-\sigma)+\sqrt{\Delta}}{2 \psi}\right)<\mu-\gamma_{T}
\end{gathered}
$$

In this case, the public debt-output ratio is in an explosive path and a greater commitment of the fiscal authority to meet the ceiling does not help the government to stabilise the public debt as a proportion of output. Figure 6.3 shows this case. 
[FIGURE 6.3 ABOUT HERE]

In short, in an economy with excessively high interest rates we have the following cases:

\section{[TABLE 2 ABOUT HERE]}

This section allows us to draw some conclusions regarding the efficacy of a government expenditure ceiling for the stabilisation of the public debt-output ratio. Comparing scenarios A and B (for developed and developing economies, respectively) we see that the implementation of a government expenditure ceiling in economies enduring excessively high interest rates, $\psi>0$, increases the propensity for public debt instability caused by the process of fiscal consolidation. Note that while in scenario A illustrating economies with sufficiently low interest rates we have one case in which the fiscal adjustment destabilises the public debt trajectory, in scenario B we have two cases wherein the public debt-output ratio becomes unstable after the fiscal tightening process.

\subsection{The role of a more progressive tax system for public debt stability}

When a cutting-based fiscal consolidation does not result in a stable level of public debtoutput ratio, policymakers may resort to tax increases. In this context, the analysis of the efficacy of different taxation strategies (regressive, proportional and progressive taxes) becomes particularly relevant. In this section we investigate, without loss of generality, the impact of a taxation strategy that burdens disproportionally low-income groups on the stability properties of the dynamics of the public debt-output ratio. In other words, we seek to assess whether a more regressive tax structure may or may not help to stabilise an unstable public debt dynamics.

Assuming the overall tax rate is kept constant $(\bar{\rho})$, a drop in the tax rate on capital income results in a proportional rise in the tax rate on labour income. By substituting equation (13) into (10) and then rearranging terms, we have:

$$
\tau_{c}=\frac{\bar{\rho}-\tau_{w} \sigma}{(1-\sigma)+\left(\eta_{0}+\eta_{1} \lambda\right) \lambda}
$$


Plugging (15) into $J_{11}$, and assuming that the fiscal authority effectively meets the ceiling $z_{\gamma}^{e}=0$, we have:

$$
J_{11}=\psi+\alpha_{1} \alpha_{0} s(1-\sigma)\left[1-\left(\frac{\bar{\rho}-\tau_{w} \sigma}{(1-\sigma)(1+\Phi)}\right)\right] \varphi
$$

where:

$$
\begin{aligned}
& \psi=\left\{1-\left[\frac{\bar{\rho}-\tau_{w} \sigma}{(1-\sigma)(1+\Phi)}\right]\right\}\left(\eta_{0}+2 \eta_{1} \lambda^{e}\right)-\alpha_{0} \gtrless 0 \\
& \varphi=\left(\frac{\lambda^{e} \mu_{\lambda}}{t^{2}}-\frac{1}{t}\right)<0 \\
& t=\Omega+s\left[1-\frac{\alpha_{1}}{1+\Phi}\right] \tau_{w} \sigma-\gamma_{T}>0 \\
& \mu_{\lambda}=-(1-s)\left(\eta_{0}+2 \eta_{1} \lambda^{e}\right)\left\{1-\left[\frac{\bar{\rho}-\tau_{w} \sigma}{(1-\sigma)(1+\Phi)}\right]\right\}<0 \\
& \Omega=(1-\sigma)-\left\{(1-s)(1-\sigma)(1+\Phi)+\alpha_{1} s(1-\sigma)\right\}\{1-\bar{\rho} /[(1-\sigma)(1+\Phi)]\} \gtrless 0 \\
& \Phi=\left[\left(\eta_{0}+\eta_{1} \lambda^{e}\right) \lambda^{e} /(1-\sigma)\right]>0
\end{aligned}
$$

Note that $\psi$ is ambiguously signed (and so a sufficiently high tax rate on labour income increases the propensity for obtaining $\psi>0$ ), $t>0$ is the stability condition in the goods market, $\mu_{\lambda}$ remains negatively signed, $\Phi$ is invariably positive, and $\Omega$ is ambiguously signed (but $\Omega>0$ makes it more likely that the stability condition in the goods market will be satisfied). The sign of $\Omega$ will not alter the outcomes of the model as long as $t$ remains positively signed.

Suppose that initially the public debt-output ratio is in an unstable trajectory, that is $J_{11}>0$. Then, what is the partial effect of a raise in the tax rate on labour income $\tau_{w}$ on the stability condition $J_{11}$ ? The partial derivative of $J_{11}$ with respect to $\tau_{w}$ is given by:

$$
\frac{\partial J_{11}}{\partial \tau_{w}}=\psi^{\prime}+\alpha_{1} \alpha_{0} s(1-\sigma)\left\{\frac{\sigma \varphi}{(1-\sigma)(1+\Phi)}+\left[1-\left(\frac{\bar{\rho}-\tau_{w} \sigma}{(1-\sigma)(1+\Phi)}\right)\right] \varphi^{\prime}\right\} \gtrless 0
$$

where:

$$
\psi^{\prime}=\frac{\left(\eta_{0}+2 \eta_{1} \lambda^{e}\right) \sigma}{(1-\sigma)(1+\Phi)}>0
$$




$$
\begin{aligned}
\varphi^{\prime} & =\frac{\lambda^{e}\left(\mu_{\lambda}^{\prime} t^{2}-2 \mu_{\lambda} t^{\prime}\right)}{t^{4}}+\frac{t^{\prime}}{t^{2}} \gtrless 0 \\
t^{\prime} & =s\left[1-\frac{\alpha_{1}}{1+\Phi}\right] \sigma>0 \\
\mu_{\lambda}^{\prime} & =-\frac{(1-s)\left(\eta_{0}+2 \eta_{1} \lambda^{e}\right) \sigma}{(1-\sigma)(1+\Phi)}<0
\end{aligned}
$$

In equation (17) the only term that contributes to a reduction in $J_{11}$ following a raise in the tax rate on labour income $\tau_{w}$ is $\mu_{\lambda}^{\prime}<0$. Therefore, an after-tax redistribution of income in favour of capital, that is a raise in $\tau_{w}$ accompanied by a proportional drop in $\tau_{c}$, increases the propensity for obtaining an explosive public debt-output trajectory over time. In other words, everything else constant, more regressive tax structures that disproportionally burdens low-income households may reduce the effectiveness of the fiscal austerity measures. In terms of policy, this results show that a more progressive tax system may be a key contributing factor to the stabilisation of the level of public debt as a proportion of output.

\section{Conclusions}

This paper reassesses the efficacy of a binding ceiling on government expenditure in promoting the sustainability of public debt in a macromodel along neo-Kaleckian lines.

The proponents of the conventional view on public debt argue that the implementation of a government expenditure ceiling may help economies enduring unsustainable public debt trajectories to achieve public debt stability over time. However, our empirical and theoretical frameworks show that by merely setting a limit for public spending without including interest payments under the ceiling may not ensure a non-explosive trajectory of the public debt-to-output ratio, particularly in the case of developing countries enduring high levels of interest rates and more regressive taxation systems. Further, we demonstrate as well that a less regressive taxation structure may increase the propensity of the system to a stable public debt dynamics. In short, we show that the implementation of a ceiling on public spending is more likely to reinforce the stability conditions of the public debt-tooutput ratio in economies where the public debt trajectory is already in a stable path. In economies where the level of public indebtedness is in an explosive trajectory, the 
contribution of a government expenditure ceiling to the stabilisation of the public debt seems to be less effective.

Lastly, one may argue that our model rests on some restrictive hypotheses such as fixed wages and prices, absence of credit to firms, no external sector, and no revision of the government expenditure ceiling. In fact, relaxing such assumptions may create a number of interesting scenarios, especially some incorporating fixed and floating exchange rate regimes, inflation and inflationary tax in an economy possibly operating at full capacity as well, and different revision rules for a non-binding ceiling on public expenditure. However interesting, given our focus on the derivation of a first set of clear-cut analytical results, we leave these questions for future research.

\section{Reference}

Ayuso-i-Casals, J. 2012. National expenditure rules: why, how and when, Economic Papers, 473 (Brussels: European Commission).

Arestis, P., and Sawyer, M. 2003. 'Reinventing fiscal policy', Journal of Post Keynesian Economics, 26: 3-25.

Badiger, H. 2009. Fiscal rules, discretionary fiscal policy and macroeconomic stability: an empirical assessment for OECD countries, Applied Economics, vol. 41, no 7, p. 829-847.

Debrun, X., L. Moulin, A. Turrini, J., Ayuso-i-Casals, and M. S. Kumar, 2008, "Tied to the mast? the role of national fiscal rules in the European Union," Economic Policy, Vol. 54, pp. 297-362.

Dequech, D. 2013. Is money a convention and/or a creature of the State? The convention of acceptability, the State, contracts, and taxes. Journal of Post Keynesian Economics, vol. 36, no. 2, p. 251-273.

Dutt, A.K. 1984. Stagnation, income distribution and monopoly power. Cambridge Journal of Economics, vol. 8, no. 1, p. 25-40.

Hallerberg, M., Strauch, R., and von Hagen, J. 2007. The design of fiscal rules and forms of governance in European Union countries, European Journal of Political Economy, vol. 23, no 2, p. 338-359.

Hein, E. 2007. Interest rate, debt, distribution and capital accumulation in a post-kaleckian model, Metroeconomica, vol. 58, 310-339

Hein, E. 2016. Autonomous government expenditure growth, deficits, debt and distribution in a neo-Kaleckian growth model. Working Paper, Institute for International Political Economy Berlin, no. 68.

Hein, E., and Stockhammer, E. 2011. A post-Keynesian macroeconomic model of inflation, distribution and employment, in Hein, E. and Stockhammer, E. (eds), A modern guide to Keynesian macroeconomics and economic policies, Cheltenham, UK and Northampton, MA, USA: Edward Elgar, 112-136.

Kalecki M. 1971. Selected Essays on the Dynamics of the Capitalist Economy, Cambridge University Press, Cambridge. 
Koenker, R. and Bassett Jr., G. 1978. Regression quantiles, Econometrica, No 46, vol 1, p. 33-50

Kopits, G., and Symansky, S. 1998. Fiscal Policy Rules, IMF Occasional Paper No. 162 (Washington: International Monetary Fund).

Ljungman, G. 2008. Expenditure ceilings - a survey, IMF Working Paper (Washington: International Monetary Fund).

Lima, G.T. and Meirelles, A.J.A. 2007. Macrodynamics of debt regimes, financial instability and growth, Cambridge Journal of Economics, vol. 31, p. 563-580

Milesi-Ferreti, G.M. 2003. Good, bad or ugly? On the effects of fiscal rules with creative accounting, Journal of Public Economics, vol. 88, p. 377-394.

Palley, T.I. 2013. Cambridge and neo-Kaleckian growth and distribution theory: comparison with an application to fiscal policy, Review of Keynesian Economics, vol. 1, no 1, p. 79-104.

Perotti, R. 2005. Estimating the Effects of Fiscal Policy in OECD Countries, CEPR Discussion Paper No. 4842 (London: Centre for Economic Policy Research).

Robinson J. 1956. The Accumulation of Capital, Macmillan, London.

Robinson J. 1962. Essays in the Theory of Economic Growth, Macmillan, London.

Ros, J. 1994. 'Foreign exchange and fiscal constraints on growth: a reconsideration of structuralist and macroeconomic approaches', in Dutt, A.K. (ed.), New Directions in Analytical Political Economy, Edward Elgar, Aldershot.

Schaechter, A., Kinda, T., Budina, N., and Weber, A. 2012, Fiscal Rules in Response to the Crisis - Toward the "Next-Generation" Rules. A New Dataset, IMF Working Paper, no 12/187, (Washington, DC: International Monetary Fund).

Setterfield, M. 2007. Is there a stabilizing role for fiscal policy in the New Consensus?, Review of Political Economy, 19 (3): 405-418.

Skott, P. 2016. Aggregate demand, functional finance, and secular stagnation, European Journal of Economics and Economic Policies: Intervention, vol. 13, no 2, p. 172-188.

Steindl, J. 1952. Maturity and Stagnation in American Capitalism, Oxford, Blackwell.

Tcherneva, P.R. 2012. Inflationary and distributional effects of alternative fiscal policies: an augmented Minskyan-Kaleckian model. Working Paper No. 706.

Von Hagen, J. 1991. A note on the empirical effectiveness of formal fiscal restraints. Journal of Public Economics, vol. 44, p. 199-210.

Von Hagen, J., and Wolff, G.B. 2006. What do deficits tell us about debt? Empirical evidence on creative accounting with fiscal rules in the EU, Journal of Banking \& Finance, vol. 30, no 12, p. 3259-3279.

Wierts, P., 2008, How do expenditure rules affect fiscal behaviour?. DNB Working Paper 166 (Amsterdam: De Nederlandsche Bank).

Wray, L.R. Understanding Modern Money. Cheltenham, UK: Elgar, 1998.

You, J., and Dutt, A.K. 1996. Government debt, income distribution and growth. Cambridge Journal of Economics, 20 (3): 335-351. 


\section{Appendix 1}

[TABLE APPENDIX 1]

\section{Appendix 2}

[TABLE APPENDIX 2]

\section{Appendix 3}

\section{[TABLE APPENDIX 3]}

The Panel Unit Root test proposed by Im et al (2003) was chosen as it is the most appropriate technique for unbalanced panels. Note that the evidence of non-stationarity of the variable Debt in level is mixed for the sample of developed countries, while it seems unambiguously non-stationary for developing countries. Thus, we take the first difference of this variable before estimating the econometric model. The test also suggests that variable GGNL is stationary in developed countries, but the results for developing countries are inconclusive. In this case we decided to include the variable in level in the baseline equation in order to favour comparability between the estimates of both groups of countries. Lastly, the test shows that the variable Growth is invariably stationary. 


\section{FIGURES}

Figure 1. Quantile panel data estimation for advanced countries
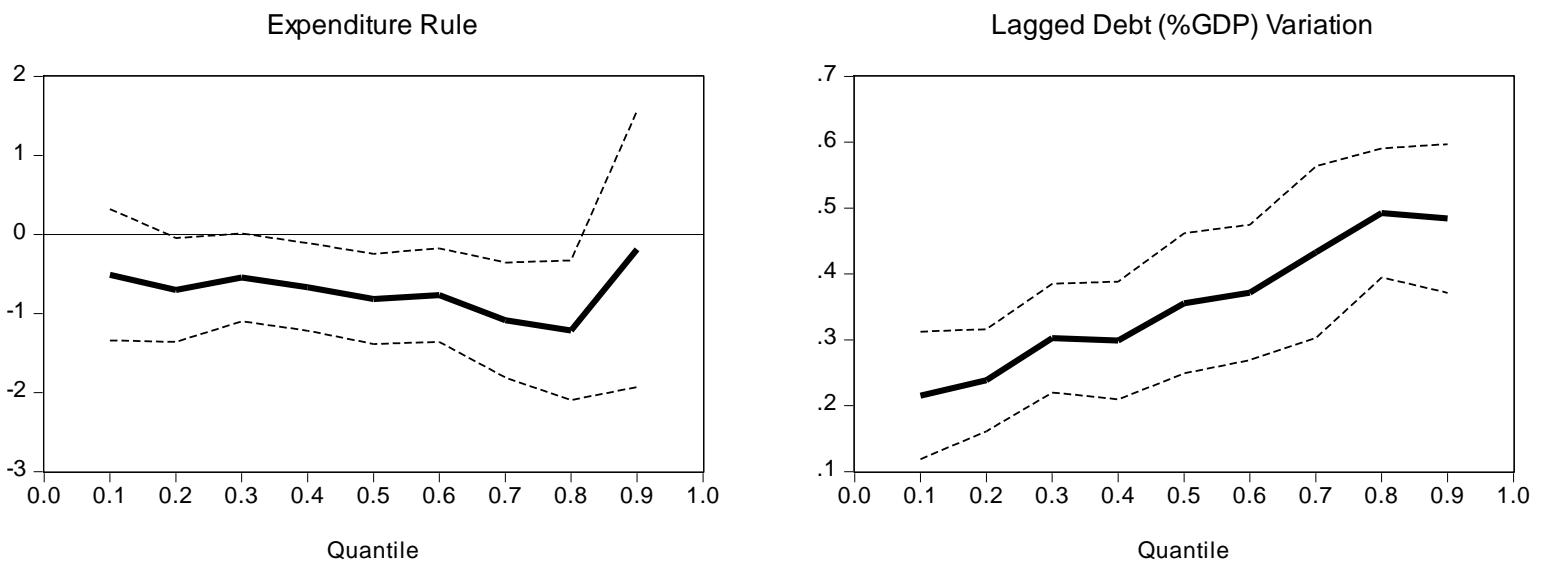

General Government Net Lending (\%GDP)
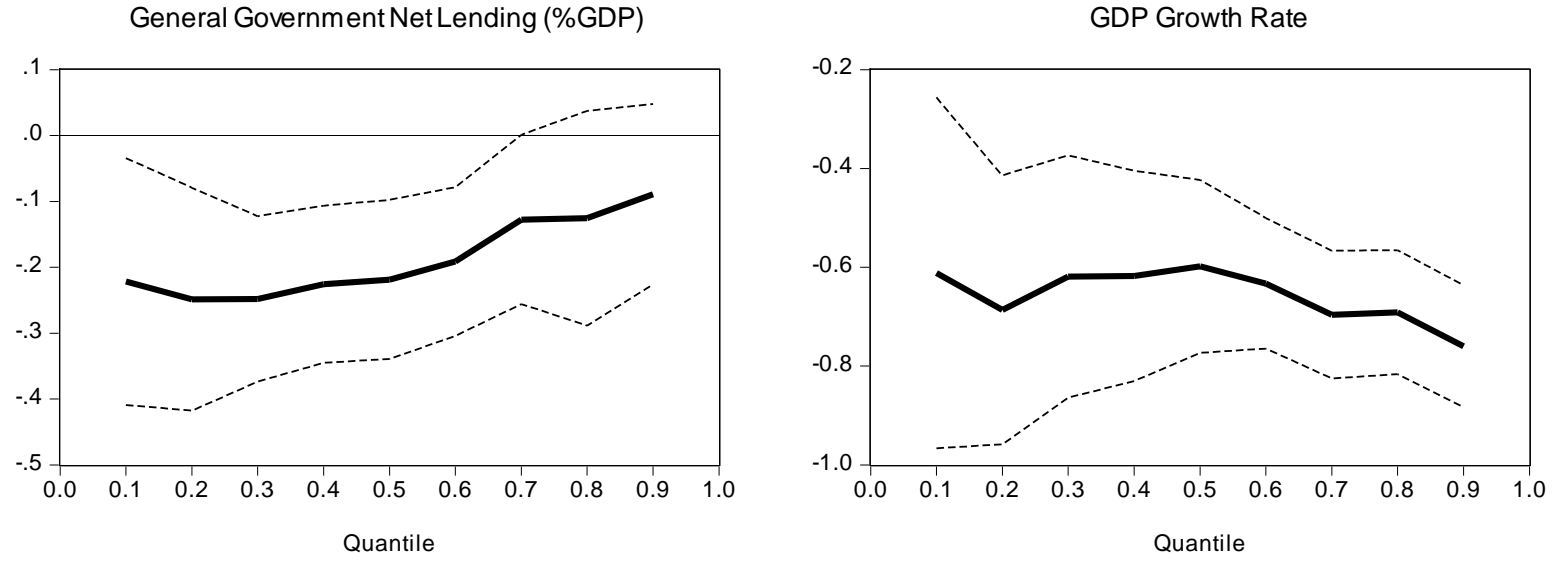
Figure 2. Quantile panel data estimation for emerging countries

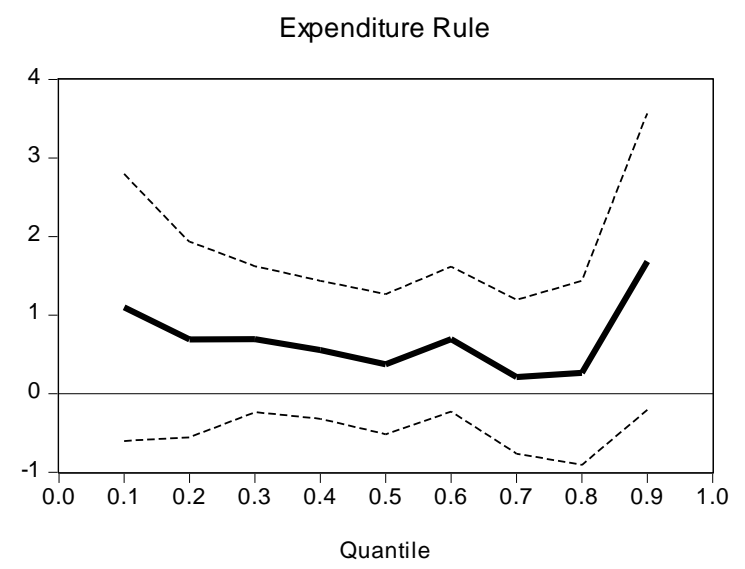

General Government Net Lending (\%GDP)

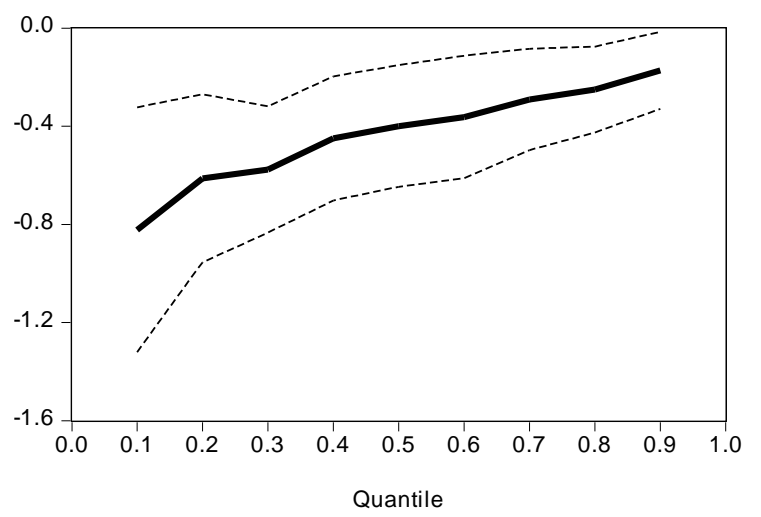

Lagged Debt (\%GDP) Variation

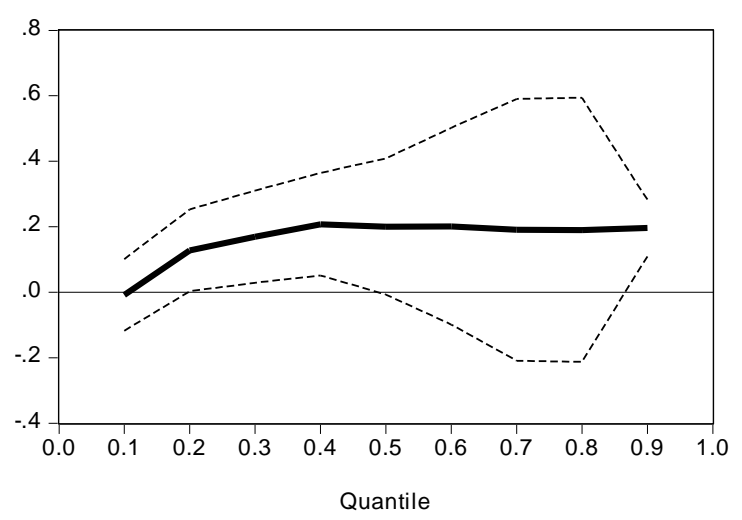

GDP Growth Rate

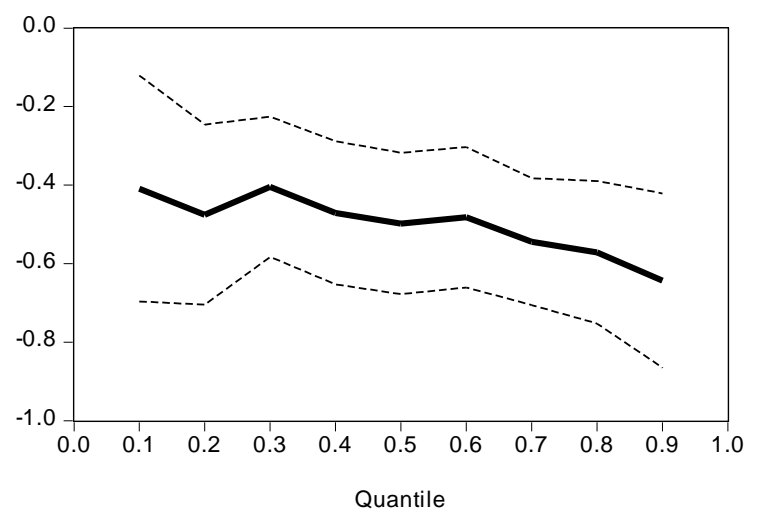


Figure 3. Unstable debt dynamics in the long run $\left(J_{11}>0\right)$

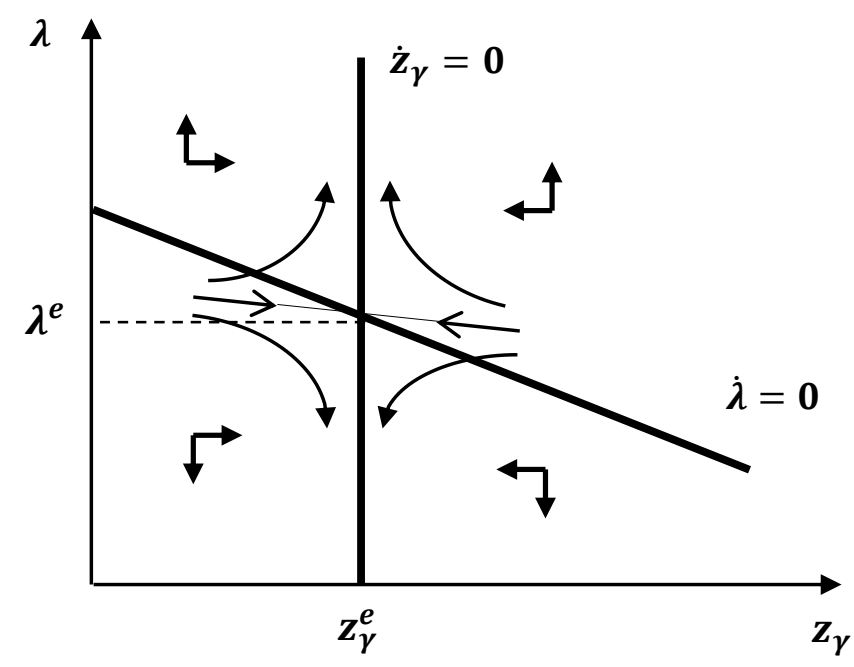

Figure 4. Stable debt dynamics in the long run $\left(J_{11}<0\right)$

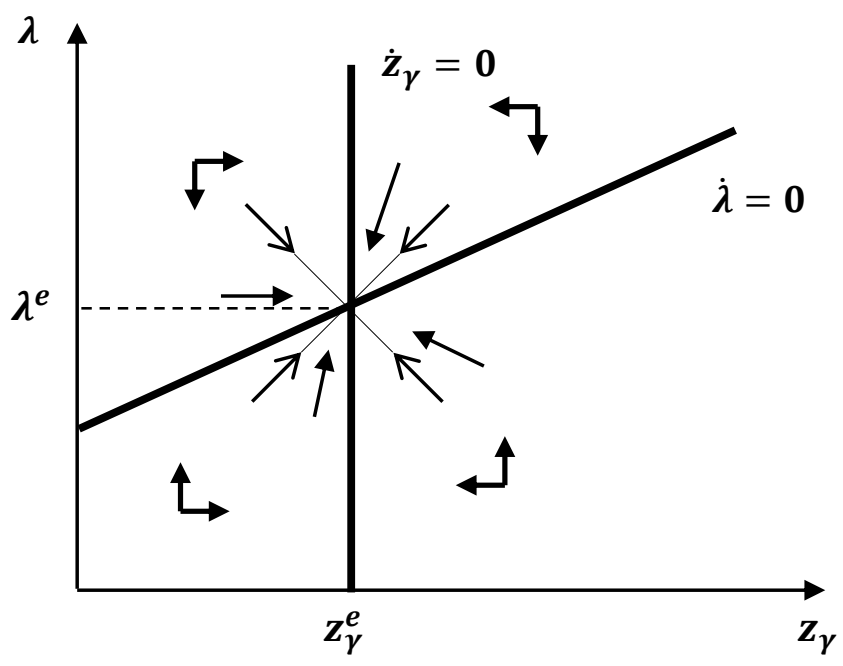


Figure 5. Stability analysis for $\psi<0$

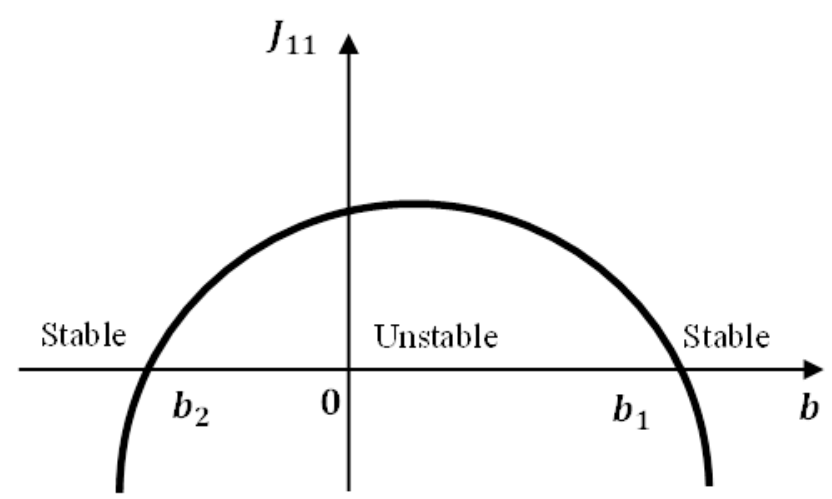

Figure 5.1. Case 1

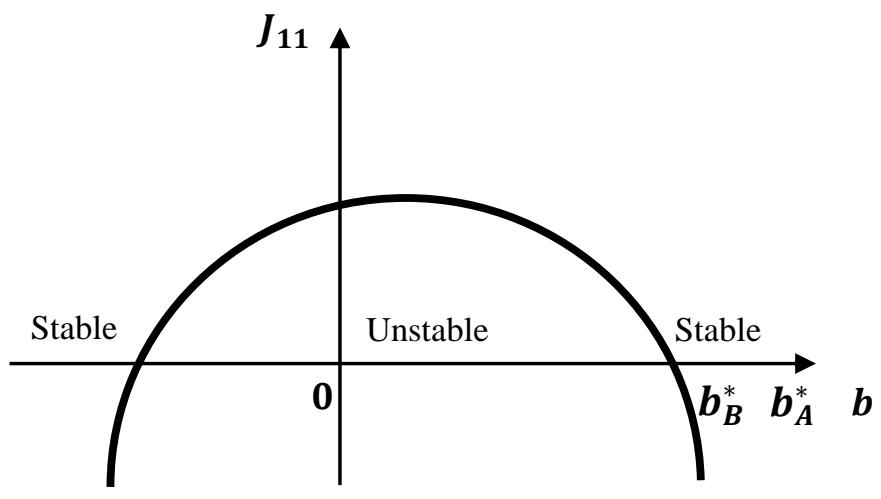

Figure 5.2. Case 2

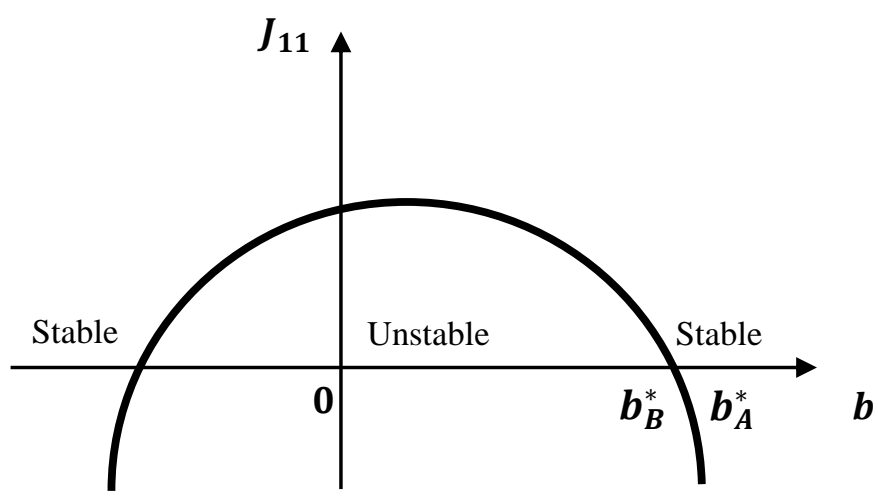


Figure 5.3. Case 3

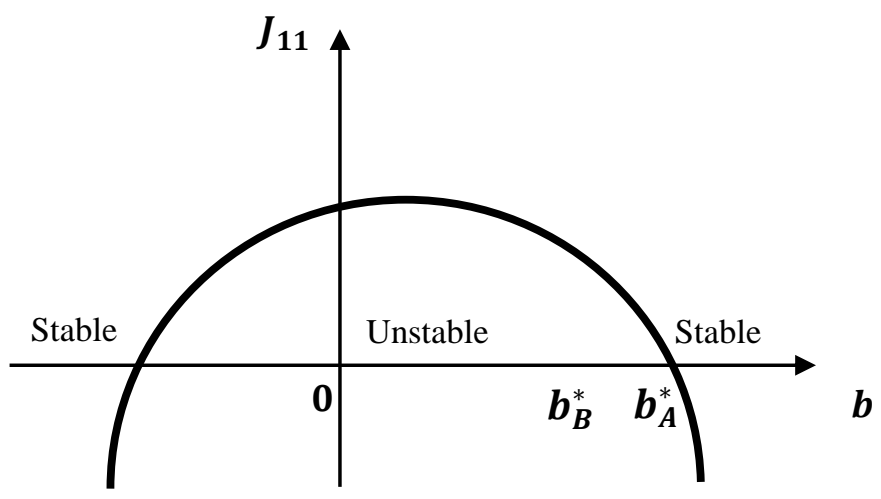

Figure 6. Stability analysis for $\psi>0$

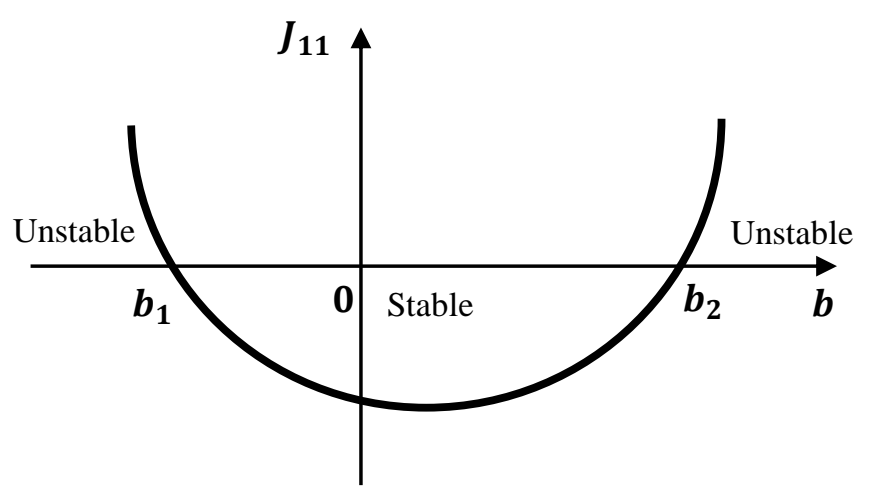

Figure 6.1. Case 1

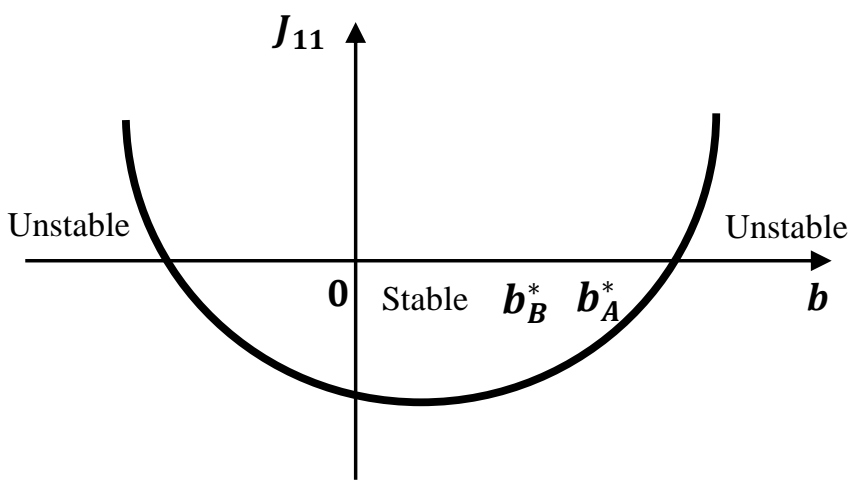


Figure 6.2. Case 2

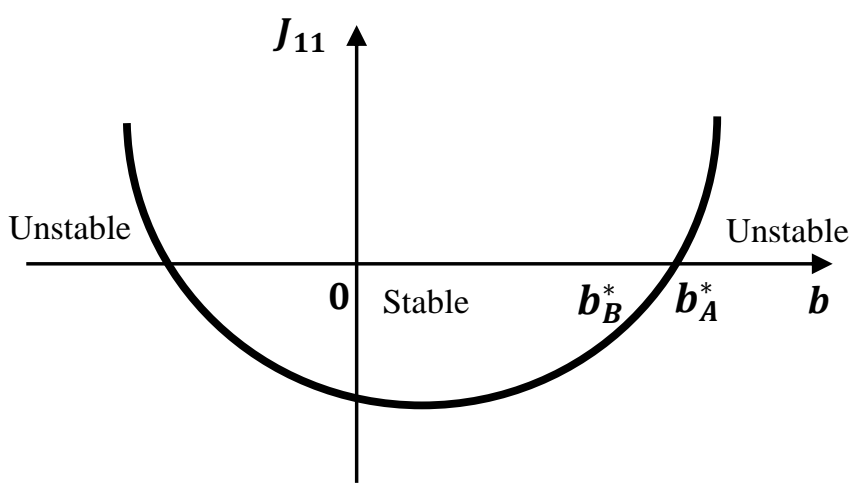

Figure 6.3. Case 3

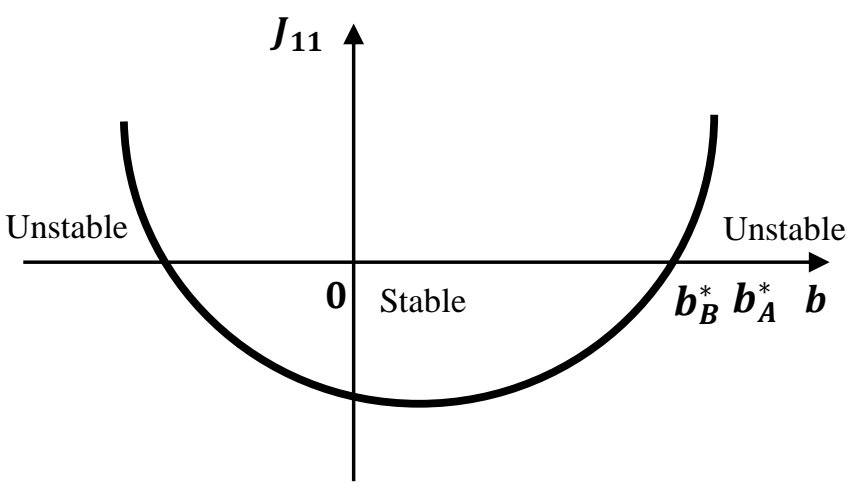




\section{TABLES}

Table 1. Summary of the stability analysis for $\psi<0$

\begin{tabular}{cccc}
\hline \hline Expenditure gap & \multicolumn{3}{c}{$\boldsymbol{\psi} \mathbf{0}$} \\
& Case 1 & Case 2 & Case 3 \\
\cline { 2 - 3 }$\left(z_{\gamma}^{e}=z_{\gamma B}^{*}>0\right)$ & Stable & Unstable & Unstable \\
After the fiscal adjustment & & & \\
$\left(z_{\gamma}^{e}=z_{\gamma A}^{*}=0\right)$ & Stable & Stable & Unstable \\
\hline \hline
\end{tabular}

Table 2. Summary of the stability analysis for $\psi>0$

\begin{tabular}{cccc}
\hline \hline Expenditure gap & \multicolumn{3}{c}{$\boldsymbol{\psi}>\mathbf{0}$} \\
\cline { 2 - 4 } & Case 1 & Case 2 & Case 3 \\
\hline Before the fiscal adjustment & Stable & Stable & Unstable \\
$\left(z_{\gamma}^{e}=z_{\gamma B}^{*}>0\right)$ & & & \\
After the fiscal adjustment & Stable & Unstable & Unstable \\
$\left(z_{\gamma}^{e}=z_{\gamma A}^{*}=0\right)$ & & & \\
\hline \hline
\end{tabular}


Table Appendix 1

\begin{tabular}{lll}
\hline \hline & \multicolumn{1}{c}{ List of developed countries } & \\
\hline Australia & Germany & Netherlands \\
Austria & Greece & Portugal \\
Belgium & Iceland & Singapore \\
Canada & Ireland & Slovak Republic \\
Cyprus & Israel & Slovenia \\
Czech Republic & Italy & Spain \\
Denmark & Japan & Sweden \\
Estonia & Latvia & United Kingdom \\
Finland & Lithuania & United States \\
France & Luxembourg & \\
\hline \hline & & \\
\hline \hline & List of developing countries & \\
\hline Argentina & Pcuador & Paraguay \\
Botswana & Georgia & Peru \\
Brazil & Hungary & Romania \\
Bulgaria & Malta & Russia \\
Colombia & Mexico & \\
Croatia & Namibia & \\
\hline \hline
\end{tabular}

Table Appendix 2

\begin{tabular}{|c|c|c|}
\hline Name & Description & Source \\
\hline Debt & $\begin{array}{l}\text { General government gross debt (\% GDP) consists of all liabilities that require } \\
\text { payment or payments of interest and/or principal by the debtor to the creditor at a } \\
\text { date or dates in the future. This includes debt liabilities in the form of SDRs, } \\
\text { currency and deposits, debt securities, loans, insurance, pensions and standardised } \\
\text { guarantee schemes, and other accounts payable. }\end{array}$ & $\begin{array}{l}\text { IMF, WEO } \\
\text { Database, } \\
\text { April } 2017\end{array}$ \\
\hline$E R$ & $\begin{array}{l}\text { Expenditure rules set limits on total, primary, or current spending. Such limits are } \\
\text { typically set in absolute terms or growth rates, and occasionally in percent of } \\
\text { GDP with a time horizon ranging often between three to five years (Schaechter et } \\
\text { al, 2012). }\end{array}$ & $\begin{array}{l}\text { IMF Fiscal } \\
\text { Rules } \\
\text { Dataset, } 2016\end{array}$ \\
\hline$G G N L$ & $\begin{array}{l}\text { General government net lending }(+) / \text { borrowing }(-)(\% \text { GDP) is calculated as } \\
\text { revenue minus total expenditure. This balance may be viewed as an indicator of } \\
\text { the financial impact of general government activity on the rest of the economy } \\
\text { and nonresidents. }\end{array}$ & $\begin{array}{l}\text { IMF, WEO } \\
\text { Database, } \\
\text { April } 2017\end{array}$ \\
\hline Growth & $\begin{array}{l}\text { Gross domestic product, constant prices (percent change). The base year is } \\
\text { country-specific. Expenditure-based GDP is total final expenditures at } \\
\text { purchasers' prices (including the f.o.b. value of exports of goods and services), } \\
\text { less the f.o.b. value of imports of goods and services. }\end{array}$ & $\begin{array}{l}\text { IMF, WEO } \\
\text { Database, } \\
\text { April } 2017\end{array}$ \\
\hline
\end{tabular}




\section{Table Appendix 3}

Panel Unit Root Test (Im, Pesaran and Shin, 2003)

\begin{tabular}{lcccc}
\hline \hline \multirow{2}{*}{ Variables } & \multicolumn{2}{c}{ Developed countries } & \multicolumn{2}{c}{ Developing countries } \\
\cline { 2 - 5 } Debt & Individual intercept & $\begin{array}{c}\text { Individual intercept } \\
\text { and trend }\end{array}$ & Individual intercept & $\begin{array}{c}\text { Individual intercept } \\
\text { and trend }\end{array}$ \\
\multirow{2}{*}{ D Debt } & 0.728 & -2.091 & -1.259 & 1.207 \\
& $(0.767)$ & $(0.018)$ & $(0.104)$ & $(0.886)$ \\
GGNL & -10.193 & -6.861 & -4.634 & -3.233 \\
& $(0.000)$ & $(0.000)$ & $(0.000)$ & $(0.000)$ \\
Growth & -7.079 & -4.694 & -3.253 & -0.715 \\
& $(0.000)$ & $(0.000)$ & $(0.000)$ & $-0.237)$ \\
\hline \hline
\end{tabular}

Notes: The null hypothesis is that the variable follows a unit root process in all groups, while the alternative hypothesis is that at least in one group the variable is stationary. In order to control for potential autocorrelation and cross-sectional dependence in the residuals, we included lagged differences of in each test. The choice of lags was based in the Schwartz information criterion. We report the p-values in brackets below the test statistics. 